\title{
Numerical Simulation of flow field optimization in Flue Gas Desulfurization Tower with Wet Spray
}

\author{
Q Wu'*, J Zhou' ${ }^{1 *}$ M Han², L Cui' \\ 1. Tangshan Worldwide Ship Equipment Co., Ltd., \\ Tangshan, Hebei 063000, China \\ 2. College of Mechanical and Electrical Engineering, Beijing \\ University of Chemical Technology, Beijing 100029, China
}

\begin{abstract}
The combustion of fossil fuels will not only produce a lot of carbon dioxide, but also convert sulfur into sulfur dioxide, which will seriously pollute the atmosphere. Rapid and efficient desulfurization is very important for enterprises that consume a lot of fossil fuels. This paper briefly introduced the sulfur removal principle and the mathematical model of flue gas flow of the wet spray method. After that, the flow field of the desulfurization tower before and after optimization was simulated by ABAQUS software, and the model test was carried out under the similar condition by using the model whose scale was reduced 10 times. The results showed that the velocity distribution of the spray layer and smoke outlet in the section velocity distribution map obtained by numerical simulation was not even and the velocity distribution after optimization was obviously uniform, while the velocity distribution of the demisting layer before and after optimization was relatively uniform and had little change. The results obtained by the test of the model with the reduced scale were close to the numerical simulation results, and the removal rate of sulfur dioxide was greatly improved after optimization.
\end{abstract}

\section{INTRODUCTION}

The rapid development of economy cannot be separated from the development of real industry. In the rapid development of industry, extensive development mode [1] inevitably causes damages to the environment, especially in heavy industry-intensive areas in China. Although a large amount of GDP is created, the local environment has been seriously damaged. The development of heavy industry will consume a large amount of fossil fuels and produce industrial waste gases. Regardless of the large proportion of $\mathrm{CO}_{2}$, the direct discharge of $\mathrm{SO}_{2}$ from the waste gases into the atmosphere will pollute the atmosphere. Once $\mathrm{SO}_{2}$ is involved in the water cycle of the atmosphere, the acid rain [2] will seriously damage the local ecological environment and cause immeasurable economic losses. Therefore, the national standards for atmospheric emissions are becoming strict, and enterprises are gradually adopting more efficient waste gas purification technology.

${ }^{*}$ Corresponding Author: qlinwu@yeah.net 
Flue gas desulfurization is divided into wet process, semi-wet process and dry process [3], and their basic principles are similar: $\mathrm{SO}_{2}$ neutralizes with alkaline substance, producing less harmful sulfate or sulfite to remove $\mathrm{SO}_{2}$ from flue gas. Warych et al. [4] constructed the desulfurization process and cost calculation model of wet lime flue gas desulfurization system to obtain the optimal process parameters under different environments. The experimental results verified the validity of the model. Wang et al. [5] simulated the two-phase flow field of sintered flue gas desulfurization tower using ANSYS CFX software. The simulation results showed that the gas-liquid contact time was long when the flow field was uniform, and the pressure drop mainly occurred in the absorption zone, which provides a reference for improving the desulfurization efficiency of the desulfurization tower. Qi et al. [6] simulated the running conditions of a sintering plant using ANSYS CFX and studied the flow fields without and with fluid spray of a full-scale ammonia-based wet flue gas desulfurization (WFGD) double tower. The results showed that the flow of spray in the double tower was more uniform, and the flow rate in the inlet area of the desulfurization tower was lower than that of the desulfurization tower without spray. This paper briefly introduced the principle of Sulphur removal and the mathematical model of flue gas flow of the wet spray method. After that, ABAQUS software was used to simulate the flow field of the desulfurization tower before and after optimization. The model whose scale was reduced 10 times was tested under the similar conditions.

\section{DESULFURIZATION BY WET SPRAY}

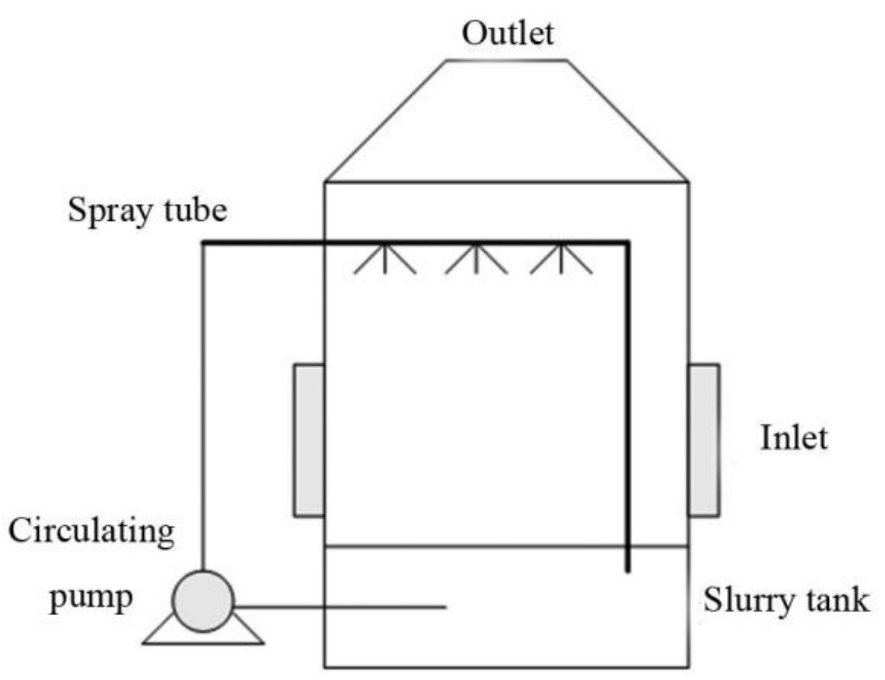

Figure 1 Schematic diagram of desulfurization by wet spray method 
The desulfurization principle model of the wet spray method is shown in Figure 1. The desulfurization system of the wet spray method is similar, which can be broadly divided into slurry tank, sulfur removal zone, circulating pump, spray tube, inlet and outlet. When wet spray is used, the industrial flue gas enters from the inlet and moves to the outlet from the bottom to the top. In the process, the circulating pump delivers the neutralizing liquid or absorbent to the spray tube downward from the slurry tank to absorb the $\mathrm{SO}_{2}$ in the upward flue gas and fall back to the slurry pool [7]. In this study, magnesium desulfurization is used. The chemical reactions in the desulfurization process are as follows:

$$
\left\{\begin{array}{l}
\mathrm{MgO}+\mathrm{H}_{2} \mathrm{O} \Leftrightarrow \mathrm{Mg}^{2+}+2 \mathrm{OH}^{-} \\
\mathrm{SO}_{2}+\mathrm{H}_{2} \mathrm{O} \Leftrightarrow \mathrm{H}^{+}+\mathrm{HSO}_{3}^{-} \\
\mathrm{HSO}_{3}^{-}+\frac{1}{2} \mathrm{O}_{2}=\mathrm{H}^{+}+\mathrm{SO}_{4}^{2-} \\
\mathrm{Mg}^{2+}+\mathrm{SO}_{4}^{2-}=\mathrm{MgSO}_{4}
\end{array}\right.
$$

\section{MATHEMATICAL MODEL OF FLUE GAS FLOW}

The research subject is the flow field in the flue gas desulfurization tower. It is assumed that the desulfurization tower works stably, the flue gas flow is stable, and the flue gas is Newton fluid, then the flow of the flue gas belongs to the single phase continuous flow, which satisfies the hypothesis of continuous medium, and the macroscopic physical quantity in the desulfurization tower is continuous and differentiable in time and space. Flue gas flow follows the conservation of mass, momentum and energy. Then the continuity equation of mass conservation which describes flue gas flow [8] is as shown in Equation (1),

$$
\frac{\partial \rho}{\partial t}+\nabla(\rho \vec{u})=S_{M}
$$

where $\rho$ stands for fluid density, $t$ stands for flow time, $\vec{u}$ stands for the velocity of flow, and $S_{M}$ is the continuous phase mass source. It is assumed that the stress on the fluid is the static pressure, then according to the principle that the stress on the fluid is proportional to the strain rate, the N-S equation describing the momentum conservation of the fluid [9] is as shown in Equation (2),

$$
\frac{\partial\left(\rho u_{i}\right)}{\partial t}+\nabla\left(\rho u_{i} \vec{u}\right)=-\frac{\partial p}{\partial i}+\nabla\left(\mu \nabla u_{i}\right)+S_{M, i}
$$

where $u_{i}$ stands for component velocity of fluid in the direction of $i, p$ stands for the static pressure on the fluid, $i$ stands for the length of the $i$-th direction, $\mu$ stands for the kinetic viscosity of fluid, and $S_{M, i}$ stands for the component momentum source of the fluid in the direction of $i$. The equation describing the fluid energy conservation [10] is as shown in Equation (3), 


$$
\frac{\partial(\rho e)}{\partial t}+\nabla(\rho e \vec{u})=-p \nabla \vec{u}+\nabla(\lambda \nabla T)+S_{\text {diss }}+S_{e n}
$$

where $e$ stands for the internal energy of the fluid per unit volume, $\lambda$ stands for the heat conductivity coefficient of

$$
\frac{\partial(\rho e)}{\partial t}+\nabla(\rho e \vec{u})=-p \nabla \vec{u}+\nabla(\lambda \nabla T)+S_{d i s s}+S_{e n},
$$

$T$ stands for temperature, $S_{\text {diss }}$ stands for the loss caused by viscous stress, $S$ stands for energy source.

Fluid flow is divided into laminar flow, transition flow and turbulence flow according to its Reynolds number [11]. The smaller the Reynolds number, the closer it is to laminar flow. Laminar flow is the ideal flow mode of fluid, and there is almost no loss caused by collision or friction. However, in practical engineering, the fluid is basically turbulence flow. In the above governing equations of mass, momentum and energy, the governing equations of mass and energy describe the overall change of flow field and do not need to distinguish directions; therefore, it is relatively simple to solve. However, the governing equation of momentum need to distinguish directions. The fluid in turbulent state is disordered and random, and it is difficult to solve the N-S equation directly. Therefore equation (2) is processed by Reynolds average and introduced with turbulence model [12], as shown in Equation (4),

$$
\left\{\begin{array}{l}
\frac{\partial\left(\rho \bar{u}_{x}\right)}{\partial t}+\nabla\left(\rho \bar{u}_{x} \vec{u}\right)=-\frac{\partial p}{\partial x}+\nabla\left(\mu \nabla \bar{u}_{x}\right)+\left(\frac{\partial \tau_{x x}}{\partial x}+\frac{\partial \tau_{x y}}{\partial y}+\frac{\partial \tau_{x z}}{\partial z}\right)+S_{M, x} \\
\frac{\partial\left(\rho \bar{u}_{y}\right)}{\partial t}+\nabla\left(\rho \bar{u}_{y} \vec{u}\right)=-\frac{\partial p}{\partial y}+\nabla\left(\mu \nabla \bar{u}_{y}\right)+\left(\frac{\partial \tau_{y x}}{\partial x}+\frac{\partial \tau_{y y}}{\partial y}+\frac{\partial \tau_{y z}}{\partial z}\right)+S_{M, y} \\
\frac{\partial\left(\rho \bar{u}_{z}\right)}{\partial t}+\nabla\left(\rho \bar{u}_{z} \vec{u}\right)=-\frac{\partial p}{\partial z}+\nabla\left(\mu \nabla \bar{u}_{z}\right)+\left(\frac{\partial \tau_{z x}}{\partial x}+\frac{\partial \tau_{z y}}{\partial y}+\frac{\partial \tau_{z z}}{\partial z}\right)+S_{M, z} \\
\tau_{i j}^{\prime}=\mu_{t}\left(\frac{\partial \bar{u}_{i}}{\partial x_{j}}+\frac{\partial \bar{u}_{j}}{\partial x_{i}}\right)+\frac{2}{3}\left(\rho k+\mu_{t} \frac{\partial \bar{u}_{i}}{\partial x_{i}}\right) \delta_{i j} \\
\mu_{t}=\rho C_{\mu} \frac{k^{2}}{\varepsilon} \\
\frac{\partial(\rho k)}{\partial t}+\nabla(\rho k \vec{u})=\nabla\left(\left(\mu+\frac{\mu_{t}}{\sigma_{k}}\right) \nabla k\right)+P_{k}-\rho \varepsilon \\
\frac{\partial(\rho \varepsilon)}{\partial t}+\nabla(\rho \varepsilon \vec{u})=\nabla\left(\left(\mu+\frac{\mu_{t}}{\sigma_{\varepsilon}}\right) \nabla k\right)+\frac{\varepsilon}{k}\left(C_{\varepsilon 1} P_{k}-C_{\varepsilon 2} \rho \varepsilon\right)
\end{array}\right.
$$


where $\bar{u}_{x}, \bar{u}_{y}, \bar{u}_{z}$ stands for the mean value of the component velocity in the direction of $x, y$ and $z, \tau_{i j}^{\prime}$ stands for the Reynolds stress term, $i$ and $j$ stand for direction $i$ and $j$, both of which can take the direction of $x, y$ and $z, \mu_{t}$ stands for eddy viscosity, $x_{i}$ and $x_{j}$ stand for the length in the direction of $i$ and $j, k$ stands for turbulence kinetic energy, and $\delta_{i j}$ stands for Kronecker product, 1 when $i=j$ and 0 when it takes other values, $C_{\mu}, C_{\varepsilon 1}$ and $C_{\varepsilon 2}$ are empirical constants, $\varepsilon$ stands for the turbulent dissipation rate, $P_{k}$ is the turbulent product of viscosity force and buoyancy, $\sigma_{k}$ is the Prandtl number of turbulence kinetic energy, and $\sigma_{\varepsilon}$ is the Prandtl number of of turbulent dissipation rate.

\section{NUMERICAL SIMULATION}

\subsection{Experimental Environment}

In this study, the flue gas flow field in the desulfurization tower which applied wet spray was simulated using the ABAQUS software [13]. The simulation experiment was carried out on the laboratory server with Windows7, Core I7 and 16G memory.

\subsection{Experimental Parameters}

The structure model of desulfurization tower before and after optimization is shown in Figure 2. The structure of desulfurization tower before optimization included two-layer demister, three-layer spray layer, one smoke inlet and one smoke outlet. The smoke inlet was round, with a diameter of $5 \mathrm{~m}$. The smoke outlet was rectangular, with a size of $7 \times 5 \mathrm{~m}^{2}$. The main body of the desulfurization tower was $30 \mathrm{~m}$ high and had a diameter of $16 \mathrm{~m}$, the distribution heights of three spray layers were 12, 14, $16 \mathrm{~m}$, and the distribution heights of two demisting layers were 19 and $22 \mathrm{~m}$. The optimized desulfurization tower added three porous distributors [14] to the original infrastructure, and the distribution heights were 11.5, 13.5 and $15.5 \mathrm{~m}$.

The simulation model was established based on the aforementioned actual size. The model was processed by grid division using hexahedron by taking the center axis of the tower as $\mathrm{Z}$ axis, the liquid level diameter of the slurry pool perpendicular to the inlet surface as $\mathrm{X}$ axis, and the diameter perpendicular to $\mathrm{X}$ axis at the liquid level of the slurry pool as $\mathrm{Y}$ axis. There were totally 540 thousand grids.

The following conditions were set:

1) Flue gas flow was stable when the desulfurization tower works;

2) The influence of temperature change on flow field was neglected;

3) The effects of spray liquid in the spray layer, demister and porous distributor on fluid were equivalent to porous media;

4) The smoke inlet had $2200 \mathrm{~m}^{3} / \mathrm{h}$ uniform flow rate, $17 \mathrm{~m} / \mathrm{s}$ initial velocity and $50^{\circ} \mathrm{C}$, which is the velocity inlet boundary; 
5) The smoke outlet was the boundary of pressure outlet;

6) The circulating flow rate of the spray layer was $1000 \mathrm{~m}^{3} / \mathrm{h}$;

7) The density and dynamic viscosity of flue gas were consistent with the mixed air in the following model tests.

8) The wall of desulfurization tower and the surface of internal components were non-sliding wall boundary.

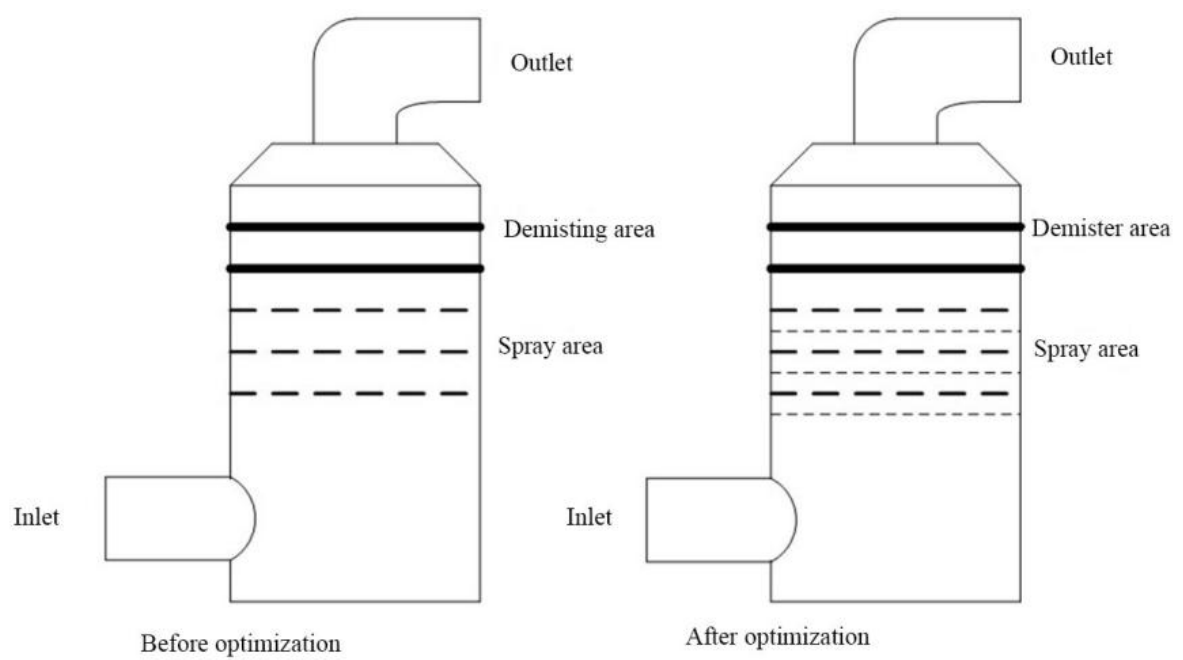

Figure 2 The calculation model of desulfurization tower before and after optimization

Moreover, a model which was reduced 10 times was built according to the desulfurization tower scheme before and after optimization. The model test followed the principles of geometry, motion and dynamic similarity: The flue gas was replaced with $\mathrm{SO}_{2}$ at $50{ }^{\circ} \mathrm{C}$, with a density of $1.122 \mathrm{~kg} / \mathrm{m}^{3}$ and dynamic viscosity of $1.678 \times 10-5 \mathrm{Ns} / \mathrm{m} 2$; aerodynamic power was provided by blower, gas flow and initial velocity were consistent with the simulation conditions; $\mathrm{MgO}$ was used as absorbent and dissolved in water to provide circulating aqueous solution using pump, and the circulating flow rate was consistent with the simulation conditions; the inlet velocity of the spray area, the inlet velocity of the demisting area and the outlet velocity were measured by anemometer; the total pressure of the inlet and outlet was measured by pitot tube; the $\mathrm{SO}_{2}$ content of the inlet and outlet was detected by $\mathrm{SO}_{2}$ detector.

Relative standard deviation [15] is used to reflect the uniformity of flue gas interfacial velocity. The smaller the numerical value, the more uniform the distribution. The formula is as follows in Equation (5),

$$
C=\frac{1}{\bar{V}} \sqrt{\frac{\sum_{i=1}^{n}\left(V_{i}-\bar{V}\right)}{n}}
$$


where $V_{i}$ stands for the velocity at some point in the cross section, $\bar{V}$ is the average velocity of cross section, and $n$ is the number of measuring points of cross section.

\subsection{Experimental Results}

The numerical simulation results of the inlet velocity distribution of the spray layer before and after the optimization of the desulfurization tower are shown in Figure 3. The velocity distribution of the flue gas field at the inlet section of the spray layer parallel to the liquid level at the bottom of the tower can be clearly seen from Figure 3. Most of the flue gas at the inlet section of the spray layer before optimization was in a speed of $3.30 \sim 4.00 \mathrm{~m} / \mathrm{s}$, and the other was $4.11 \sim 4.33 \mathrm{~m} / \mathrm{s}$. The velocity of some flue gas near the tower wall was about $2.12 \mathrm{~m} / \mathrm{s}$. The velocity distribution is not uniform. The relative standard deviation, $C$, after statistics, was $18.6 \%$. The velocity distribution of the spray layer inlet section after optimization became uniform. The general trend was that the velocity increased gradually from outside to inside, and there was no such situation that distribution of high velocity was dense in half of the area and distribution of low velocity was dense in the other area. The relative standard deviation, $C$, was $8.6 \%$.
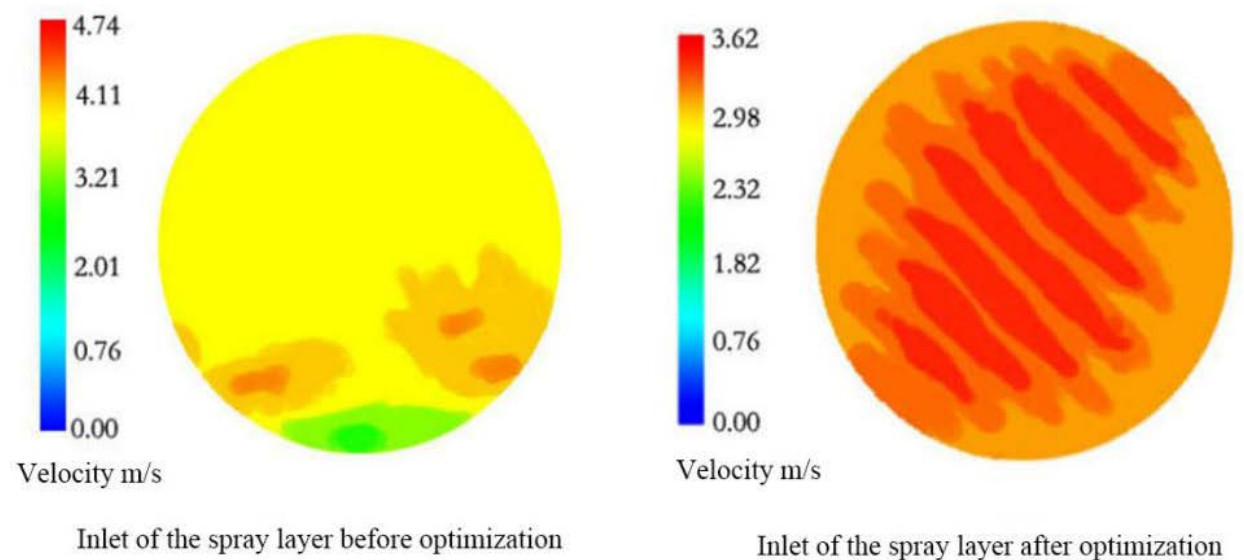

Inlet of the spray layer after optimization

Figure 3 The inlet velocity of the spray layer under two schemes in numerical simulation

The numerical simulation results of the inlet velocity distribution of the demisting layer before and after the optimization of the desulfurization tower are shown in Figure 4. The velocity distribution of the flue gas field at the inlet section of the demisting layer parallel to the liquid level at the bottom of the tower can be seen intuitively from Figure 4. By comparing the velocity distributions of the inlet of the demisting layer before and after optimization, it can be found that the velocity distributions were similar, both of them were gradually increasing from the outside to the inside, the distributions of different velocity regions were symmetrical as a whole, and there was no case of one side being dense while the other side being sparse. 
The statistics showed that relative deviation $C$ of inlet velocity of the demisting layer before optimization was $12.8 \%$ and that after optimization was $12.3 \%$, which also showed that the velocity distribution of the inlet of the demisting layer had little change before and after optimization.
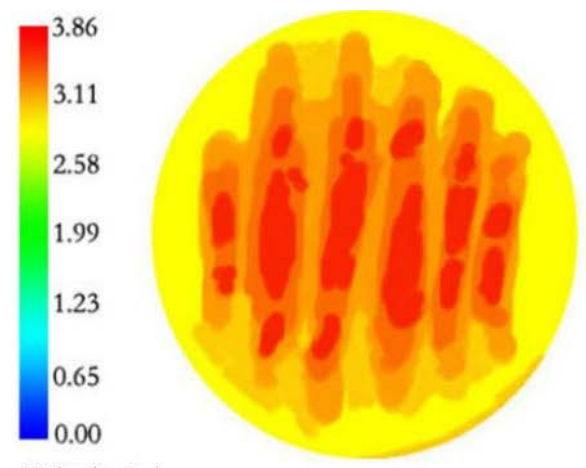

Velocity $\mathrm{m} / \mathrm{s}$
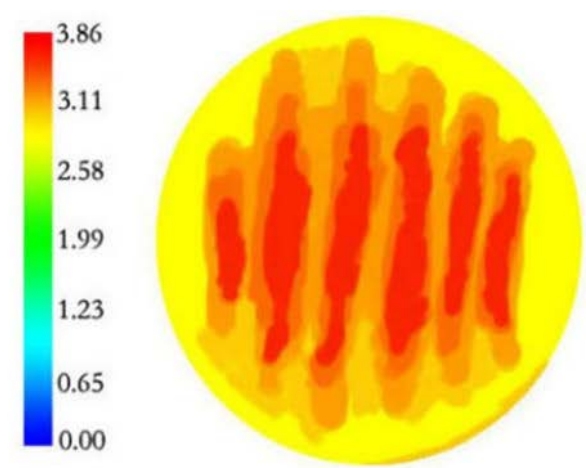

Velocity $\mathrm{m} / \mathrm{s}$

Inlet of demisting layer before optimization

Inlet of demisting layer after optimization

Figure 4 The inlet velocity of the demisting layer under two schemes in numerical simulation

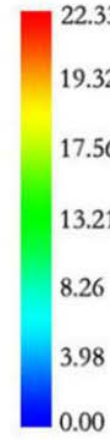

Velocity $\mathrm{m} / \mathrm{s}$

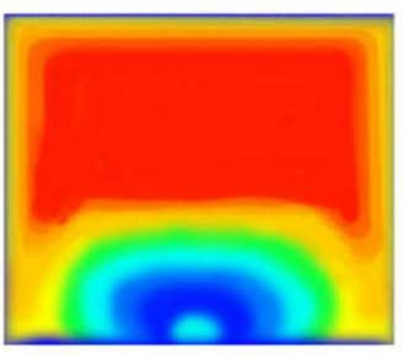

Outlet before optimization

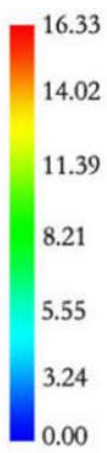

Velocity $\mathrm{m} / \mathrm{s}$

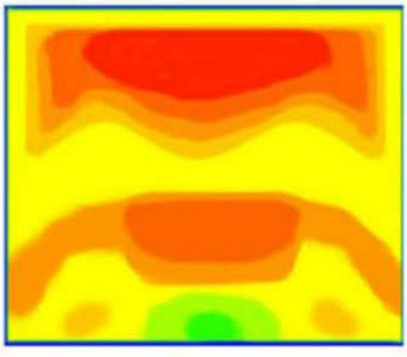

Outlet after optimization

Figure 5 The exit velocity of two schemes in numerical simulation

The numerical simulation results of the velocity distribution of the outlet before and after the optimization of the desulfurization tower are shown in Figure 5. The velocity distribution of the flue gas field at the outlet section perpendicular to the liquid level at the bottom of the tower can be seen intuitively from Figure 5. It can be seen from the velocity distribution chart of the outlet before optimization that the velocity distribution of the outlet of the desulfurization tower before optimization was very uneven when it worked, showing that the velocity of the upper air flow was large and the lower air flow had low velocity or even had no velocity. 
The statistics showed that the relative deviation of the outlet velocity was $45.6 \%$. From the velocity distribution chart of the outlet after optimization, it can be seen that the velocity distribution of the outlet was greatly improved after optimization, and the velocity of the lower part significantly improved and got close to the upper part. The statistics showed that the relative deviation of the outlet was $12.4 \%$.

Table 1 Results of model test and numerical simulation before and after optimization

\begin{tabular}{lllll}
\hline & \multicolumn{2}{c}{ Before optimization } & \multicolumn{2}{c}{ After optimization } \\
& Model test & $\begin{array}{l}\text { Numerical } \\
\text { simulation }\end{array}$ & Model test & $\begin{array}{l}\text { Numerical } \\
\text { simulation }\end{array}$ \\
\hline $\begin{array}{l}\text { Relative deviation of outlet } \\
\text { velocity /\% }\end{array}$ & 44.8 & 45.6 & 13.5 & 12.4 \\
$\begin{array}{l}\text { Relative deviation of velocity } \\
\text { in demisting layer /\% }\end{array}$ & 12.5 & 12.8 & 11.9 & 12.3 \\
$\begin{array}{l}\text { Relative deviation of spray } \\
\text { layer velocity /\% }\end{array}$ & 18.4 & 18.6 & 8.3 & 8.6 \\
$\mathrm{SO}_{2}$ Content in Inlet $\mathrm{mg} / \mathrm{m}^{3}$ & 831 & $/$ & 831 & $/$ \\
$\mathrm{SO}_{2}$ content in outlet $\mathrm{mg} / \mathrm{m}^{3}$ & 80.2 & $/$ & 12.3 & $/$ \\
\hline
\end{tabular}

In this study, the desulfurization tower model before and after optimization were constructed in the ratio of $1: 10$, and the experimental results were compared with the numerical simulation results, as shown in Table 1 . Before optimization, the relative deviation of the outlet velocity was $44.8 \%$, that of the inlet velocity of the demisting layer was $12.5 \%$, and that of the inlet velocity of the spray layer was $18.4 \%$. In numerical simulation, the relative deviation of the outlet velocity was $45.6 \%$, that of the inlet velocity of the demisting layer was $12.8 \%$, and that of the inlet velocity of the spray layer was $18.6 \%$. After optimization, the relative deviation of the outlet velocity was $13.5 \%$, that of the inlet velocity of the demisting layer was $11.9 \%$, and that of the inlet velocity of the spray layer was $8.3 \%$. In numerical simulation, the relative deviation of the outlet velocity was $12.5 \%$, that of the inlet velocity of the demisting layer was $12.3 \%$, and that of the inlet velocity of the spray layer was $8.6 \%$. By comparing the relative deviation of velocity of the outlet, demisting layer and spray layer between model test and numerical simulation and the total pressure drop of the system, it can be found that the data obtained from the model test and numerical simulation were quite close, which showed that it was feasible and effective to obtain the flue gas field in the desulfurization tower by numerical simulation. Regardless of model test or numerical simulation, the relative deviation of velocity of the flue gas outlet and spray layer of the desulfurization tower optimized according to the optimized scheme was obviously reduced, while the relative deviation of velocity of the demisting layer was reduced but not obvious. 
Generally speaking, the movement of flue gas field in the optimized desulfurization tower was more uniform, and the contact between the flue gas and spray absorbent was more sufficient, so that the desulfurization effect was better, which was also proved by the results of the model test: the $\mathrm{SO}_{2}$ content in the inlet was $831 \mathrm{mg} / \mathrm{m}^{3}$, the $\mathrm{SO}_{2}$ content in the outlet was $80.2 \mathrm{mg} / \mathrm{m}^{3}$, and the absorption rate was $90.35 \%$ before optimization; after optimization, the $\mathrm{SO}_{2}$ content in the inlet was $831 \mathrm{mg} / \mathrm{m}^{3}$, the $\mathrm{SO}_{2}$ content in the outlet was $12.3 \mathrm{mg} / \mathrm{m}^{3}$, and the absorption rate was $98.52 \%$.

\section{CONCLUSION}

This paper briefly introduced the sulfur removal principle and the mathematical model of flue gas flow of the wet spray method. After that, the flow field of the desulfurization tower before and after optimization was simulated using ABAQUS software. Moreover, model test was carried out using the model which was reduced 10 times under the similar conditions. The results are as follows. The velocity distribution of the spray layer before optimization in numerical simulation showed that the velocity distribution was uneven, and the relative deviation was $18.6 \%$; the velocity distribution of the spray layer after optimization showed that the velocity distribution was even, and the relative deviation dropped to $8.6 \%$. In the numerical simulation, the velocity distribution of the inlet of the demisting layer did change much after optimization, and the velocity distribution was uniform, with relative deviations of $12.8 \%$ and $12.3 \%$, respectively. In the numerical simulation, the velocity distribution of the outlet was uneven before optimization, with a relative deviation of $45.6 \%$. After optimization, the velocity distribution was relatively uniform, with a relative deviation of $12.4 \%$. The test results of model with the reduced scale showed that the relative deviations of velocity of the spray layer, demisting layer and outlet were close to that of numerical simulation. Moreover, the absorption rate of $\mathrm{SO}_{2}$ before optimization was $90.35 \%$, and the absorption rate of $\mathrm{SO}_{2}$ after optimization was $98.52 \%$.

\section{REFERENCES}

[1] Wang, Z., T. Guo, L. Xia and Q. Dong, Numerical simulation on circulation and absorption of sulfur dioxide inside droplet. Journal of Jiangsu University, 2017. 38(3): p. 289-294 and 301.

[2] Zou, H.K., M. Arowo, Q. Zhang, L.L. Zhang, B.C. Sun, G.W. Chu, L. Shao and J. Chen, Flue-gas Desulfurization Using a Higee-Electric Field Device. Chemical Engineering \& Technology, 2018. 41(4).

[3] Chen, B.K. and F.Z. Sun, Research on Thermal Properties of Two Phase in a Flue Gas Desulfurization Wet Scrubber. Advanced Materials Research, 2015. 1092-1093: p. 529533.

[4] Warych, J. and M. Szymanowski, Optimum Values of Process Parameters of the "Wet Limestone Flue Gas Desulfurization System”. Chemical Engineering \& Technology, 2015. 25(4): p. 427-432.

[5] Wang, S.J., P. Zhu, G. Zhang, F. Wu, Z.Y. Wang and L. Zhao, Numerical simulation research of flow field in ammonia-based wet flue gas desulfurization tower. Journal of the Energy Institute, 2015. 88(3): p. 284-291.

[6] Zhang, Q., S. Wang, P. Zhu, Z.Y. Wang and G. Zhang, Full-scale simulation of flow field in ammonia-based wet flue gas desulfurization double tower. Journal of the Energy Institute, 2017. p. S1743967116305104. 
[7] King, K.W., M.R. Williams, W.A. Dick and G.A. LaBarge, Decreasing Phosphorus Loss in Tile-Drained Landscapes Using Flue Gas Desulfurization Gypsum. Journal of Environmental Quality, 2016. 45(5): p. 1722-1730.

[8] Zhang, Z., L. Lang, J. Wang, Z. Zhang and G. Wen, Chemical Mass Transfer Mechanism and Characteristics of Flue Gas Desulfurization of Basic Aluminum Sulfate by Bubbles. Energy \& Fuels, 2017. 31(10): p. 11043-11052.

[9] Qi, Z., K. Gui and X. Wang, Effects of magnetic fields on improving mass transfer in flue gas desulfurization using a fluidized bed. Heat \& Mass Transfer, 2016. 52(2): p. 331-336.

[10] Min, C., X. Deng and F. He, Study on the kinetics of S(IV) oxidation in the basic aluminum sulfate wet flue gas desulfurization process. RSC Advances, 2017. 7(62): p. 39341-39348.

[11] Michalovicz, L., W.A. Dick, E.C. Cervi, C.A. Tormena and M.M.L. Müller, Flue gas desulfurization gypsum as a chemical amendment to reduce the concentrations of phosphorus and suspended solids in liquid manure. Management of Environmental Quality An International Journal, 2017. 28(5): p. 00-00.

[12] Fang, P., Z.J. Tang, X.B. Chen, J.H. Huang, Z.X. Tang and C.P. Cen, Chloride Ion Removal from the Wet Flue Gas Desulfurization and Denitrification Wastewater Using Friedel's Salt Precipitation Method. Journal of Chemistry, 2018. 2018: p. 1-9.

[13] Li, G., B. Wang, W.Q. Xu, Y. Han and Q. Sun, Simultaneous removal of SO2 and NOx from flue gas by wet scrubbing using a urea solution. Environmental Technology, 2018: p. 1-29.

[14] Wang, R., H. Wang, S. Chen, Y. Qu and C. Wang, Numerical investigation of multiphase flow in flue gas desulphurization system with rotary jet stirring. Results in Physics, 2017. 7: p. 1274-1282.

[15] Su, S., L. Liu, L. Wang, S.S.A. Syed-Hassan, F. Kong, S. Hu, Y. Wang, L. Jiang, K. Xu, A. Zhang and H. Tang, Mass Flow Analysis of Mercury Transformation and Effect of Seawater Flue Gas Desulfurization on Mercury Removal in a Full-Scale Coal-Fired Power Plant. Energy \& Fuels, 2017. 31(10): p. 1109-11116. 
